Tohoku J. exp. Med., 1968, 95, 201-202

(Short Report)

\title{
Effect of Saxitoxin on Spontaneous Release of Acetyl- choline from the Frog's Motor Nerve Endings
}

\author{
Akinori Nishiyama \\ Department of Applied Physiology (Prof. T. Suzuki), \\ Tohoku University School of Medicine, Sendai
}

Saxitoxin (STX), a purified paralytic shellfish poison, has biological actions very similar to those of tetrodotoxin (TTX), a purified puffer fish poison, ${ }^{\mathbf{1}}$ although the former is chemically somewhat different from the latter. Both toxins block the generation of spike potentials in nerve and muscle fibers by interfering selectively with the initial increase in sodium permeability.2,4

On the neuromuscular junction the toxins block the neuromuscular transmission by affecting the motor axon and the muscle membrane, while they do not affect the end-plate receptor. They reduce the amplitude of end-plate potential without depolarization elicited by nerve stimulation. During this time, the end-plate membrane remains entirely responsive to locally applied acetylcholine. ${ }^{3-5}$ However, we found some discrepancies between the actions of STX and TTX on the miniature end-plate potentials (MEPP), i.e., in some cases STX produced a transient increase in the frequency of these MEPP and after a long period of immersion the amplitude of these potentials was reduced by about $40 \%{ }^{4}$

The purpose of this experiment is to know whether our previous observations are valid or not. The results show that the effect of STX on MEPP is essentially identical with that of TTX.

MEPP were recorded on the isolated frog sciatic nerve muscle preparations with almost the same technique as that of our previous paper, ${ }^{4}$ except that the bathing solution was continuously refreshed. Fig. 1 shows the records of MEPP before and after application of STX in a concentration of $1.0 \mu \mathrm{g} / \mathrm{ml}$, which is about a hundred times higher than the blocking concentration. The histograms of amplitude of MEPP in the preparation of Fig. 1 are illustrated in Fig. 2. STX did not significantly affect the amplitude of MEPP, though after a long immersion their mean amplitude was reduced by $5 \%$. The important point is that their decrease is insignificantly small in contrast with that reported previously and it may be possibly due to the muscle deterioration. The frequency of MEPP was increased up to $30 \%$ in STX in the preparation of the figures, but in the other preparations such a remarkable increase was not observed. The frequency of MEPP

Received for publication, May $27,1968$. 


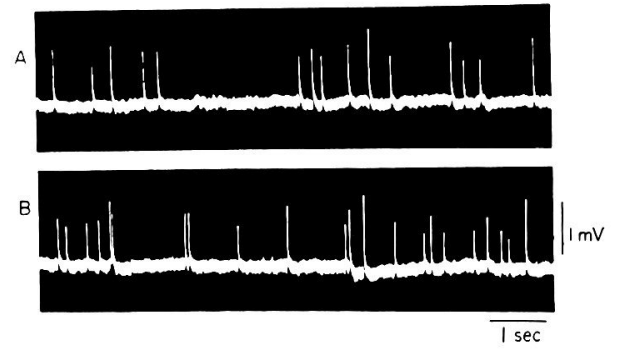

Fig. 1.
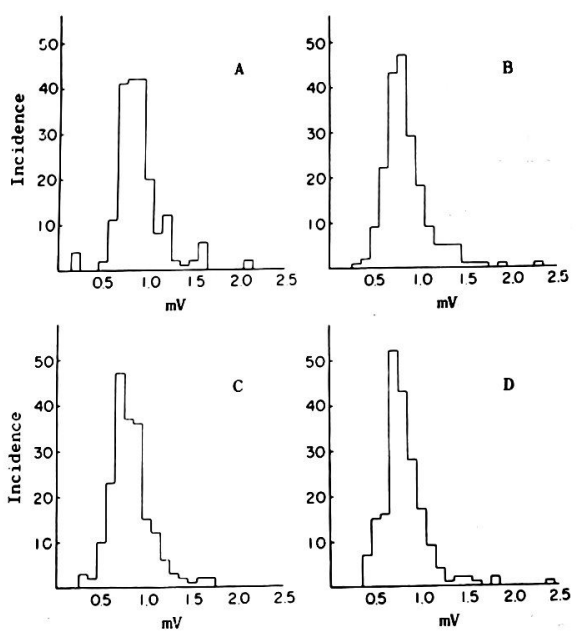

Fig. 2 .

Fig. 1. Miniature end-plate potentials at one single end-plate before and after application of $1.0 \mu \mathrm{g} / \mathrm{ml} \mathrm{STX.} \mathrm{A,} \mathrm{control;} \mathrm{B,} 30 \mathrm{~min}$ after application of the toxin. $3.6 \mathrm{mmolar}$ calcium was contained in saline solution.

Fig. 2. Histograms of miniature end-plate potentials before and after application of STX; preparation of Fig. 1 .
A: Control $\mathrm{F}=82 / \mathrm{min}$
$\mathrm{A}=0.85 \mathrm{mV}$
B: $\quad$ STX $1.0 \mu \mathrm{g} / \mathrm{ml}, 20 \mathrm{~min}$
$\mathbf{F}=117 / \mathrm{min}$
C: STX $1.0 \mu \mathrm{g} / \mathrm{ml}, 30 \mathrm{~min}$
$\mathrm{F}=114 / \mathrm{min}$
$\mathrm{A}=0.85 \mathrm{mV}$
D: STX $1.0 \mu \mathrm{g} / \mathrm{ml}, 40 \mathrm{~min}$
$\mathrm{F}=107 / \mathrm{min} \quad \mathrm{A}=0.80 \mathrm{mV}$
$\mathrm{F}$ represents mean frequency and $\mathrm{A}$ mean amplitude of 200 random but successive counts.

was markedly increased in STX by raising the external sodium concentration to twice the normal.

Our final conclusion is that STX has no significant effect on either spontaneous release of the acetylcholine packets from the nerve terminals or their quantum size, which coincides with those of TTX reported on the rat muscle ${ }^{6}$ and on the frog muscle. ${ }^{7}$

\section{References}

1) Kao, C.Y. Tetrodotoxin, saxitoxin and their significance in the study of excitable phenomena. Pharmacol. Rev., 1966, 18, 997-1049.

2) Narahashi, T., Haas, H.G. \& Therrien, E.F. Saxitoxin and tetrodotoxin: Comparison of nerve blocking mechanism. Science, 1967, 157, 1441-1442.

3) Furukawa, T., Sasaoka, T. \& Hosoya, Y. Effects of tetrodotoxin on the neuromuscular junction. Jap. J. Physiol., 1959, 9, 143-152.

4) Kao, C.Y. \& Nishiyama, A. Actions of saxitoxin on peripheral neuromuscular systems. J. Physiol., 1965, 180, 50-66.

5) Nishiyama, A. Effect of saxitoxin on the end plate of frog muscle. Nature (Lond.), $1967,215,201-202$.

6) Elmqvist, D. \& Feldman, D.S. Spontaneous activity at a mammalian neuromuscular junction in tetrodotoxin. Acta physiol. scand., 1965, 64, 475-476.

7) Katz, B. \& Miledi, R. Tetrodotoxin and neuromuscular transmission. Proc. roy. Soc. B., 1967, 167, 8-22. 